\title{
Neuronal Differentiation of Mouse Neural Crest Cells in Vitro
}

\author{
Kazuo Ito*, Toshiteru Morita ${ }^{1}$ and Takuji Takeuchi \\ Biological Institute, Tohoku University, Aoba-Yama, Sendai 980, and ${ }^{1}$ College \\ of General Education, Department of Biology, Osaka University, Toyonaka, \\ Osaka 560, Japan
}

\begin{abstract}
The purpose of the present study is to analyze the effect of serum or chick embryo extract (CEE) on the neuronal differentiation of the mouse neural crest cells. When the crest cells were cultured in the medium containing serum at low concentration ( $5 \%$ calf serum), neurite outgrowth was observed. The active outgrowth was detected at 3-4 days in culture. However, in the medium supplemented with $20 \%$ calf serum, no neurite appeared, and the crest cells remained fibroblast-like. The differentiation of adrenergic neurons was observed when the crest cells were cultured in the medium containing CEE along with serum.
\end{abstract}

The neural crest, a transient structure in the neural primordium of the vertebrate embryo, originates on the dorsal surface of the neural tube. Neural crest cells migrate extensively in the early embryonic stage and give rise to various tissues such as autonomic and sensory neurons, adrenal medulla, melanocytes, and cranial and facial connective tissues $(4,6,10)$. Recently, in avian neural crest cells, it has been shown that the developmental potential of individual crest cells is heterogeneous $(1,8)$. It has also suggested that the differentiation of avian neural crest cells in vitro depends on the composition of the culture medium and substrate $(3,7,9,11,12)$. In the present study, we investigated the effect of serum and CEE on the differentiation of the mouse neural crest cells.

\section{MATERIALS AND METHODS}

As animals for the study, C57BL/6 strain was used. The cultures of the mouse neural crest cells were prepared according to Ito and Takeuchi (5). In brief, the caudal segments of 9-day mouse embryos were excised and trypsinized. The neural tubes were removed from the surrounding tissues and placed into $35 \mathrm{~mm}$ culture dishes containing $2 \mathrm{ml}$ of the culture medium (see below). The neural tubes were carefully detached from the dishes with tungsten needles and discarded after 2 days in culture. The cultures were incubated at $37^{\circ} \mathrm{C}$ in a humidified atmosphere of $5 \% \mathrm{CO}_{2}$ in air. The medium containing serum at low concentration consisted of Eagle's minimum essential medium (MEM), and 5\% calf serum (CS, Flow). The medium containing serum at high concentration consisted of $80 \%$ MEM and $20 \%$ CS. CEE was prepared from the trunks of 10-day chick embryos. After washing chick embryos in Tyrode solution,

\footnotetext{
* Present address: College of General Education, Department of Biology, Osaka University, Toyonaka, Osaka 560, Japan
} 
they were homogenized, and then mixed with a equal volume of Tyrode solution. The mixture was freeze-thawed three times, and centrifuged twice at 3,000 r.p.m. for $15 \mathrm{~min}$. The resulting supernatant was used as CEE. Intracellular catecholamine (CA) was detected by the formaldehyde-induced fluorescence (FIF) method (2). The cultures were quenched in isopentan cooled with liquid nitrogen, freeze-dried for $1 \mathrm{~h}$, and then exposed to formaldehyde gas at $80^{\circ} \mathrm{C}$ for $1 \mathrm{~h}$. CA fluorescence was viewed with an Olympus fluorescence microscope.

\section{RESULTS AND DISCUSSION}

When the neural crest cells were cultured in the medium containing the serum at high concentration (20\%), all the cells in culture appeared to be fibroblast-like. This morphological feature remained throughout the culture period (Fig. 1a). In the medium with CS at low concentration (5\%), however, the cultures developed in a different direction. After 2-3 days in culture, numerous crest cells started to become ovoid, extended neurite-like processes, and exhibited a typical neuronal appearance. The number of these cells gradually increased. The neurons with refractive, ovoid cell bodies clustered in small ganglia within $24 \mathrm{~h}$. After 3-4 days in culture, these ganglia were connected with each other by long processes to form a neuronal network (Fig. 1b). This network structure remained for 3 or 4 days in culture. When the crest cells were cultured in the medium containing $20 \%$ serum for the first 2 days and then in the medium supplemented with $5 \%$ serum, the neuronal network was observed within 1-2 days after the change of serum concentration (Fig. $2 \mathrm{a}, \mathrm{b})$. The morphology of the network was comparable to that differentiated from the crest cells cultured in the medium containing 5\% CS for the whole culture period. In the previous study, we showed that CA-positive adrenergic neurons differentiated in the culture condition that both serum and CEE were present (5). In order to examine the effect of CEE or serum on CA synthesis in the neural crest cells in culture, CEE was added to the medium. When the medium with $5 \% \mathrm{CS}$ was supplemented with $4 \% \mathrm{CEE}$, numerous crest cells migrated from the explanted neural tubes within $24 \mathrm{~h}$ in culture. After 3 days in culture, small ganglion-like cell clumps were observed. These cell clumps gradually increased in number and volume. Neurite-like processes were found at 4-6 days in culture. These processes mainly distributed in the area surrounding ganglion-like structures (Fig. 3), though they were short and thin (Fig. 3). In order to detect CA, FIF was performed at 6 days in culture. Table 1 shows the number of the colonies with CA-positive cells. It is clear that the differentiation of the crest cells into CA-positive neurons is promoted by addition of $\mathrm{CEE}$ to the medium. In the medium containing $\mathrm{CEE}$,

TABLE 1. THE DifFERENTIATION OF THE MOUSE NEURAL CREST CELlS INTO CA-POSITIVE ADRENERGIC NEURONS

\begin{tabular}{cccc}
\hline Culture condition & $5 \%$ serum & $20 \%$ serum & $5 \%$ serum $+4 \%$ CEE \\
\hline $\begin{array}{c}\text { Number of colonies } \\
\text { with CA-positive neurons } \\
\text { total colonies }\end{array}$ & $0 / 15$ & $2 / 14$ & $6 / 6$ \\
& $(0 \%)$ & $(14 \%)$ & $(100 \%)$ \\
\hline
\end{tabular}

CA-positive adrenergic neurons were detected by FIF method at 6-day culture period. The neural crest outgrowth from an explanted neural tube was regarded as one colony. 

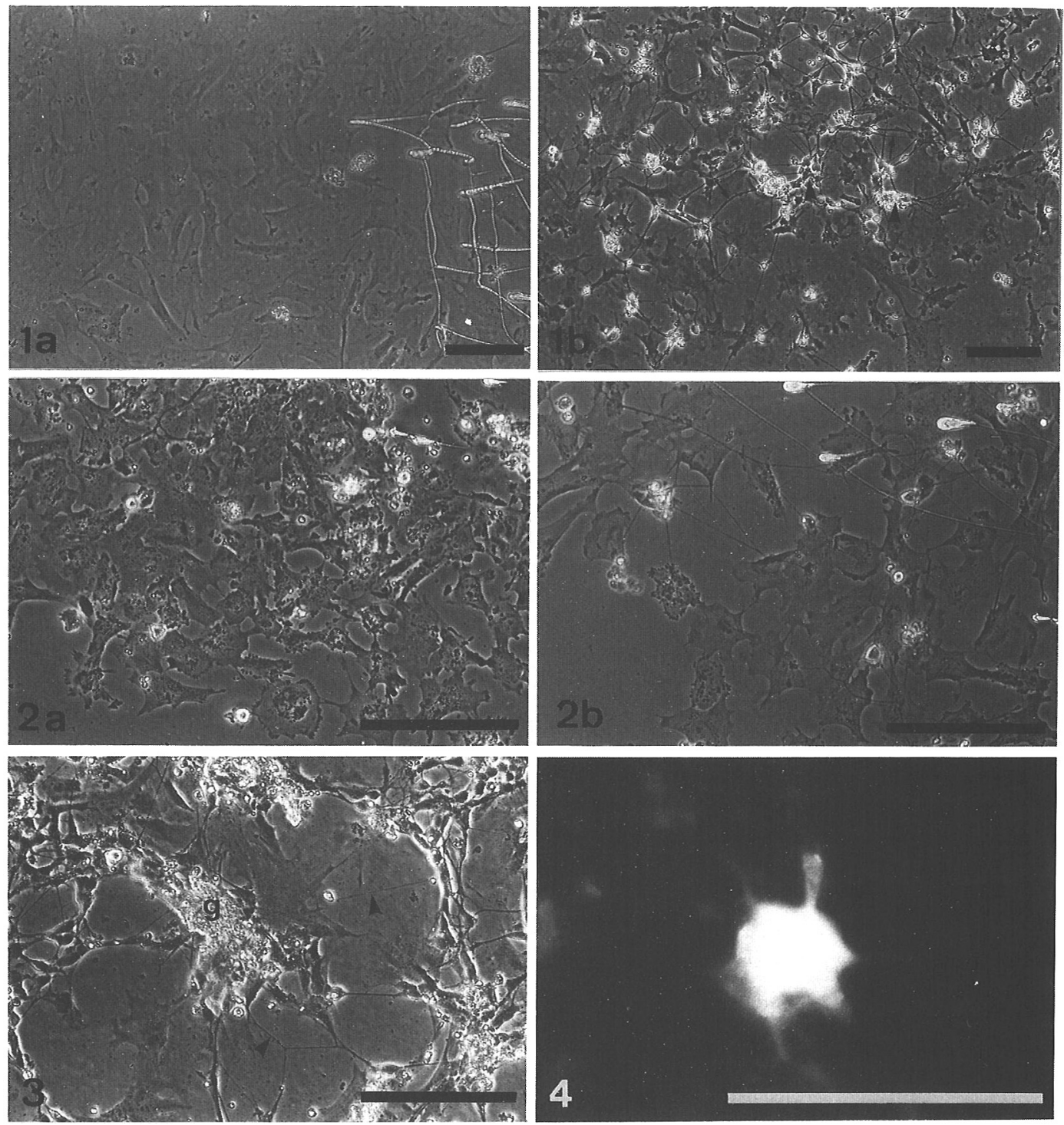

Fig. 1. The morphology of the neural crest cells at 6 days in culture under high (a) or low (b) serum conditions. Bar, $100 \mu \mathrm{m}$. (a) The crest cells in the medium with $20 \% \mathrm{CS}$. The morphology of these cells is fibroblast-like. (b) The crest cells in the medium with 5\% CS. The typical neurite-like processes (arrows) are observed. The ganglion-like structures (arrow heads) connected with these processes are also found.

Fig. 2. The neural crest cells cultured in the medium with $20 \%$ CS for first 2 days and then in the medium with $5 \% \mathrm{CS}$. Bar, $100 \mu \mathrm{m}$. (a) The crest cells immediately after the change of serum concentration. The morphology of these cells is fibroblast-like. (b) The similar field to (a) at 2 days after the change of serum concentration. The neuronal network is observed.

Fig. 3. The neural crest cells in the medium with $5 \% \mathrm{CS}$ and $4 \% \mathrm{CEE}$. The ganglion-like structures (g) after 6 days in culture. The neurite-like processes (arrow heads) distributed in the area surrounding these structures. Bar, $100 \mu \mathrm{m}$.

Fig. 4. FIF fluorescence of the ganglion-like structure at 6 days in culture. The crest cells were cultured in the medium containing CEE (4\%) along with serum (5\%). Bar, $100 \mu \mathrm{m}$. 
ganglion-like cell clusters were exclusively CA-positive (Fig. 4).

In the present study, we showed that the neuronal differentiation of premigratory trunk neural crest cells in the mouse was dependent on serum content of the culture medium. When the neural crest cells were cultured in the medium containing serum at high concentration (MEM $+20 \% \mathrm{CS}$ ), isolated neural crest cells did not exhibit a morphologically identifiable neuronal phenotype. In contrast, when cultured in the medium supplemented with serum at low concentration (MEM $+5 \% \mathrm{CS})$, a subpopulation of the crest cells readily differentiated into morphologically overt neurons. Moreover, the change of serum concentration $(20 \% \rightarrow 5 \%)$ in the early phase of the culture was followed by the appearance of the neurons. This result suggests that the precursory cells of the neurons are included in the crest cells cultured in the medium containing $20 \%$ serum. Therefore, it is clear that CS exerts the inhibitory effect on the neurite outgrowth. However, CA was neither synthesized nor stored in these neurons. The neurotransmitter(s) associated with these neurons is thus unknown. On the other hand, CA-positive adrenergic neurons mainly differentiated when CEE was added to the culture medium. Our result seems to indicate that the presence of promoting factor(s) in CEE is necessary to the expression of adrenergic phenotype of the mouse neural crest cells.

\section{REFERENCES}

1. Cohen, A.M. and I.R. Konigsberg. A clonal approach to the problem of neural crest determination. Develop. Biol. 46, 262-280, 1975

2. Falk, C. and C. Owman. A detailed methodological description of the fluorescence method for the cellular demonstration of biogenic monoamines. Acta Univ. Lund, Sect. 2, 7, 5-23, 1965

3. Glimelius, B. and J.A. Weston. Analysis of developmentally homogeneous neural crest cell population in vitro. III. Role of culture environment in cluster formation and differentiation. Cell Differ. 10, 57-67, 1981

4. Hörstadius, S. The neural crest, Oxford University Press, New York. 1950

5. Iто, K. and T. TAKeuchi. The differentiation in vitro of the neural crest cells of the mouse embryo. J. Embryol. Exp. Morph. 84, 49-62, 1984

6. Le Douarin, N.M. The neural crest, Cambridge University Press, Cambridge. 1982

7. Loring, J., B. Glimelius and J.A. Weston. Extracellular matrix materials influence quail neural crest cell differentiation in vitro. Develop. Biol. 90, 165-174, 1982

8. Siber-Blum, M. and A.M. Cohen. Clonal analysis of quail neural crest cells: they are pluripotent and differntiate in vitro in the absence of noncrest cells. Develop. Biol. 80, 96-106, 1980

9. Sieber-Blum, M., F. Sieber and K.M. Yamada. Cellular fibronectin promotes adrenergic differentiation of quail neural crest cells in vitro. Exp. Cell Res. 133, 285-295, 1981

10. Weston, J.A. The migration and differentiation of neural crest cells. In Adv. Morphogenesis, Vol. 8, pp. 41-114, 1970

11. Ziller, C., E. Dupin, P. Brazeau, D. Paulin and N.M. Le Douarin. Early segregation of a neural precursor cell line in the neural crest as revealed by culture in a chemically defined medium. Cell 32, 627-638, 1983

12. Ziller, C., M. Fauquet, C. Kalcheim, J. Smith and N.M. Le Douarin. Cell lineages in peripheral nervous system ontogeny: medium-induced modulation of neural phenotypic expression in neural crest cell cultures. Develop. Biol. 120, 101-111, 1987 